\title{
Article \\ Muscle Strength Moderates the Relationship between Nutritional Health Risk and Depression in Korean Older Adults
}

\author{
Jeonghyeon Kim ${ }^{1}$, Seamon Kang ${ }^{1}$, Haeryun Hong ${ }^{1}$, Hyunsik Kang ${ }^{1, * \mathbb{C}}$, Ju-Hyoung Kim ${ }^{2}$ and Sang-Koo Woo ${ }^{2}$ \\ 1 College of Sport Science, Sungkyunkwan University, Suwon 16419, Korea; zzagkim115@naver.com (J.K.); \\ abtkang2@gmail.com (S.K.); hhr8028@skku.edu (H.H.) \\ 2 Department of Physical Education, Andong National University, Andong 36729, Korea; \\ idno10@naver.com (J.-H.K.); exit@andong.ac.kr (S.-K.W.) \\ * Correspondence: hkang@skku.edu; Tel.: +82-31-299-6911
}

check for updates

Citation: Kim, J.; Kang, S.; Hong, H.; Kang, H.; Kim, J.-H.; Woo, S.-K. Muscle Strength Moderates the Relationship between Nutritional Health Risk and Depression in Korean Older Adults. Nutrients 2022, 14, 665. https://doi.org/10.3390/ nu14030665

Academic Editor: Francisco José Amaro-Gahete

Received: 29 December 2021 Accepted: 1 February 2022

Published: 4 February 2022

Publisher's Note: MDPI stays neutral with regard to jurisdictional claims in published maps and institutional affiliations.

Copyright: (C) 2022 by the authors. Licensee MDPI, Basel, Switzerland. This article is an open access article distributed under the terms and conditions of the Creative Commons Attribution (CC BY) license (https:// creativecommons.org/licenses/by/ $4.0 /)$.

\begin{abstract}
Background: Little is known about the relationships between muscle strength and nutritional health risk with late-in-life depression. This study aimed to investigate the moderating effect of lower-extremity muscle strength on the relationship between nutritional health risk and depression in Korean older adults. Methods: Data obtained from 5949 women and 3971 men aged $\geq 65$ years in the 2020 Korea Longitudinal Study on Aging were used in this study. Exposures included lower-extremity muscle strength and nutritional health risk. Lower-extremity muscle strength was measured with a modified sit-to-stand test. The nutritional health risk was assessed using a screening tool. Depression was defined as a score $\geq 8$ points on the Geriatric Depression Scale (GDS). Results: Logistic regression analyses showed that depression was positively associated with nutritional health risk $(p<0.001)$ and inversely associated with lower-extremity muscle strength $(p<0.001)$. A moderation analysis with Andrew Hayes' PROCESS macro showed a significant moderating effect of lower-extremity muscle strength ( $\beta=-0.119 ; 95 \%$ confidence interval, -0.172 to $-0.066 ; p<0.001)$ on the relationship between nutritional health risk and depression; the weaker was the muscle strength, the steeper was the slope of the GDS score for nutritional health risk. Conclusions: The current findings suggest the need for an intervention targeting both high nutritional risk and weak muscle strength as a therapeutic strategy against depression in Korean older adults.
\end{abstract}

Keywords: depression; nutrition; physical fitness; lifestyle risk factors; older adults; Koreans

\section{Introduction}

Depression is a serious mental disorder, affecting 3.8\% of the global population, and is a leading cause of disability worldwide, representing an important contributor to the global burden of diseases (https:/ / www.who.int/health-topics/depression/ accessed on 1 November 2021). In Korea, depression has been a major public health concern because of its devastating consequences, such as increased risks of chronic diseases [1], mental disorders [2], suicidal ideation [3], and early death [4]. Using data from the Korean national insurance system between 2011 and 2015, an estimated 2.02\% of the total Korean population had pharmaceutically treated depression (PTD), and the total medical cost of PTD was USD 1.331 billion annually [5].

Etiologically, depression is significantly correlated with a cluster of behavioral risk factors, including smoking [6], heavy alcohol consumption [7], inactivity [8], and functional limitations [9]. Together with the abovementioned risk factors, weak muscle strength has been used as an important sign of overall health [10], vulnerability [11], fall risk [12], and early death from all causes [13] in older adults. Weak muscle strength is also associated with an increased risk of late-in-life depression in Western [10] and Asian [14] older adults. 
Certain components of nutritional status, such as nutritional risk or malnourishment, are other independent risk factors to be considered in relation to the etiology of late-in-life depression. For example, a diet low in fruits and vegetables is associated with an increased risk of depression [15], while a healthy diet, including quality foods, no meat or dairy intake, and vitamin D and omega-3 supplementation, is associated with a lower incidence of depression [16]. In a case-control study involving depressed patients and age-matched healthy controls, unhealthy dietary patterns were associated with higher risks of depression, while healthy dietary patterns were associated with lower risks [17].

Relationships of depression with weak muscle strength and poor nutritional status have been found in Korean older adults [14,18-20]. Nevertheless, the prevalence and incidence of late-in-life depression vary across ages [21], perhaps due to individual variations in modifiable lifestyle risk factors. Normal aging results in declines in food consumption and nutritional intake [22,23], as well as reduced muscle mass and strength [24]. In contrast, physical activity and fitness counteract age-related declines $[25,26]$. Together, findings from previous studies suggest that both weak muscle strength and nutritional health risk are involved in the etiology of late-in-life depression. Therefore, considering both nutrition and muscle strength would provide a better picture of the complex etiology of late-in-life depression.

The current study aimed to investigate the moderating effect of lower-extremity muscle strength on the relationship between nutritional health risk and depression in Korean older adults.

\section{Materials and Methods}

\subsection{Data Source and Study Participants}

Data were obtained from the 2020 Korea Longitudinal Study on Aging (KLoSA), a nationwide-population-based survey of 6062 women and 4035 men aged $\geq 65$ years conducted in Korea. As shown in Figure 1, those without Geriatric Depression Scale (GDS) data were excluded $(n=177)$. The remaining 9920 samples (including 3971 men and 5949 women) were used for the final data analyses. The Institutional Review Board of the Korea Institute for Health and Social Affairs reviewed and approved the 2020 KLoSA (approval no. 2020-36/approved on 24 March 2020) in accordance with the Declaration of Helsinki. Signed informed consent was obtained from all participants. KLoSA data collection was carried out during face-to-face interviews via a computer-assisted personal interviewing protocol using a tablet. A detailed KLoSA information is accessible via the national public database (https: / / survey.keis.or.kr/eng/myinfo/login.jsp/ accessed 10 June 2021).

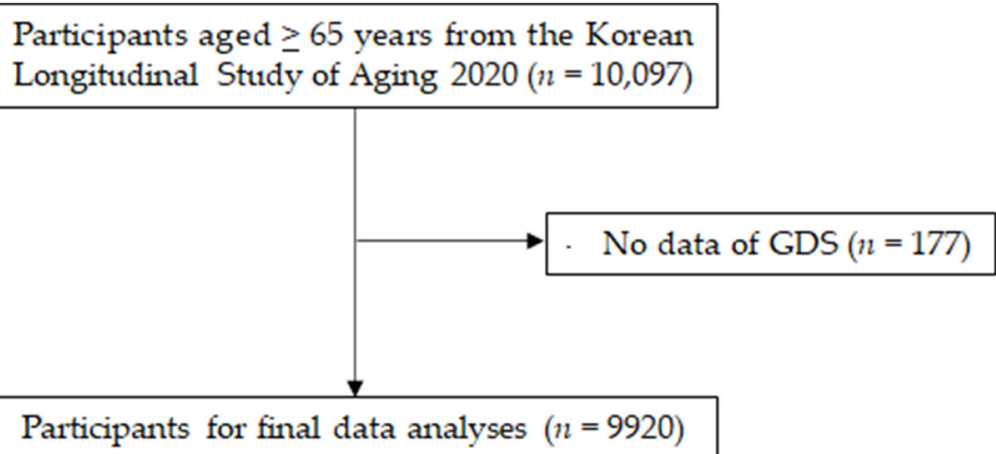

Figure 1. A flowchart for the selection of study participants. GDS; Geriatric Depression Scale.

\subsection{Variables}

\subsubsection{Depression}

Depression was assessed using a Korean version of a 15-item Geriatric Depression Scale (SGDS-K) [27]. Depression was defined as having a score of 8 or higher from the 
SGDS-K or having physician-diagnosed depression or taking anti-depressant medication(s). The cutoff score of 8 for diagnosing depression was tested and validated in previous studies involving psychiatric patients [28] and community-dwelling elderly persons [27].

\subsubsection{Nutritional Health Risk}

The nutritional health risk was assessed using the DETERMINE Your Nutritional Health Checklist developed by the Nutrition Screening Initiative [29]. The checklist consists of 14 questions with possible scores of 0 to 4 points. A total score of 0 to 21 points was calculated by summing the values attributed to each question. The nutritional health risk was then categorized as good (0-2), moderate risk (3-5), or high risk (6 or more). The accuracy of the screening tool for nutritional health risk was previously tested and validated in a sample of elderly persons [30].

\subsubsection{Lower Extremity Muscle Strength}

The sit-to-stand test developed by Buatois et al. [31] was modified to test lower extremity muscle strength. In brief, participants were instructed to stand from a sitting position on a chair or a bed 5 times as quickly as possible while keeping their arms folded across the chest. The performance was scaled according to completeness $(1=$ completed successfully, 2 = tried but failed to complete, 3 = could not perform). For convenience, "completed successfully" was categorized as indicative of strong muscle strength, and "tried but failed to complete" and "could not perform" were collapsed and categorized as indicative of weak muscle strength.

\subsubsection{Covariates}

Covariates included age (year), gender (male vs. female), body mass index (BMI) (weight in $\mathrm{kg}$, height in $\mathrm{m}^{2}$ ), educational background (<elementary, middle/high school, or $\geq$ college), smoking (current/past smoker or nonsmoker), alcohol consumption (0, 1-6, $\geq 7$ times/week), regular exercise (yes or no), and comorbidities. Patients' comorbidity status was determined using diagnoses reported by a doctor of at least one of 17 selected chronic conditions (i.e., hypertension, stroke, hyperlipidemia, heart disease, kidney disease, diabetes, cancer, hypo- or hyperthyroidism, arthritis, osteoporosis, pain/sciatica in the lower back, fracture/dislocation/accident-related residual injuries, chronic lung disease, asthma, mycobacteria/tuberculosis, dementia, and Parkinson's disease). The number of chronic conditions (comorbidities) was summed and categorized as no health condition (none), one health condition (single), and two or more health conditions (multiple).

\subsection{Statistics}

Quantile-quantile plotting and a variance inflation factor were used to verify data distribution normality and the absence of multicollinearity, respectively. Student's $t$-test and chi-squared test were used to compare continuous and categorical variables, respectively, between not depressed and depressed participants. Linear regression was used to assess the relationships between GDS scores and other variables. Multivariate logistic regression was used to estimate odds ratios (ORs) and 95\% confidence intervals (CIs) of nutritional health and lower-extremity muscle strength for depression. Finally, as illustrated in Figure 2, we examined the moderating effect of lower-extremity muscle strength (moderator, $W$ ) on the relationship between nutritional health risk (continuous, $\mathrm{X}$ ) and GDS (continuous, $\mathrm{Y}$ ) with Andrew Hayes' PROCESS macro. The statistical significance of the model was tested with bias-corrected bootstrapping $(n=5000)$ and $95 \%$ CIs. The statistical significance of a relationship was tested with a nonzero value of a $95 \%$ bootstrapped CI. All other statistical significances were tested at $p=0.05$ using SPSS version 27.0 for Windows (IBM Corporation, Armonk, NY, USA). 


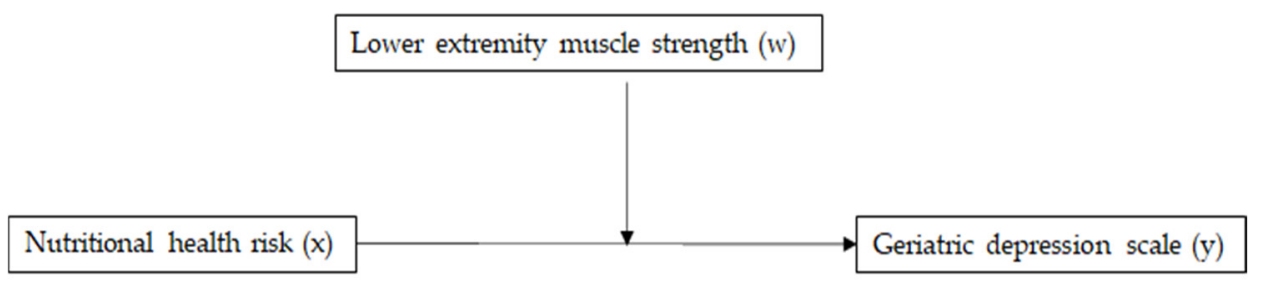

Figure 2. A conceptual diagram for the relationship between nutritional health risk (x) and Geriatric Depression Scale (y) moderated by lower extremity muscle strength (w).

\section{Results}

Table 1 presents descriptive statistics of study participants by depression status. Depressed individuals were older $(p<0.001)$ and more likely to be female $(p=0.013)$, with lower mean BMI ( $p<0.001)$, lower educational background $(p<0.001)$, weaker lowerextremity muscle strength $(p<0.001)$, and more infrequent regular exercise, greater heavy alcohol consumption $(p=0004)$, more comorbidities $(p<0.001)$, and higher nutritional health risk $(p<0.001)$, compared with nondepressed individuals.

Table 1. Descriptive statistics of study participants $(n=9920)$.

\begin{tabular}{|c|c|c|c|c|}
\hline Variables & Not Depressed $(n=9042)$ & Depressed $(n=878)$ & Effect Size & $p$ Value \\
\hline Age (years) & & & -0.217 & $<0.001$ \\
\hline $60-69$ & $3246(35.9)$ & $265(30.2)$ & & \\
\hline $70-74$ & $2276(25.2)$ & $190(21.6)$ & & \\
\hline $75-79$ & $1765(19.5)$ & $191(21.8)$ & & \\
\hline$\geq 80$ & $1755(19.4)$ & $232(26.4)$ & & \\
\hline Gender, $n(\%)$ & & & 0.025 & 0.013 \\
\hline Male & $3654(92.0)$ & $317(8.0)$ & & \\
\hline Female & 5388 (90.6) & $561(9.4)$ & & \\
\hline Body mass index $\left(\mathrm{kg} / \mathrm{m}^{2}\right)$ & $23.6 \pm 2.6$ & $23.1 \pm 2.7$ & 0.182 & $<0.001$ \\
\hline Education, $n(\%)$ & & & 0.058 & $<0.001$ \\
\hline Elementary or less & 3968 (43.9) & $463(52.7)$ & & \\
\hline Middle/high & $4590(50.8)$ & $394(44.9)$ & & \\
\hline College or higher & $484(5.4)$ & $21(2.4)$ & & \\
\hline Smoking, $n(\%)$ & & & 0.014 & 0.154 \\
\hline Nonsmokers & $8062(89.2)$ & $769(87.6)$ & & \\
\hline Current/past smokers & $980(10.8)$ & $109(12.4)$ & & \\
\hline Alcohol intake (times/week) & & & 0.004 & 0.004 \\
\hline 0 & 5735 (63.4) & $508(57.9)$ & & \\
\hline $1-6$ & 3207 (35.5) & $361(41.0)$ & & \\
\hline$\geq 7$ & $100(1.1)$ & $9(1.0)$ & & \\
\hline Regular exercise, $n(\%)$ & & & 0.053 & $<0.001$ \\
\hline Yes & $4802(53.1)$ & $385(43.8)$ & & \\
\hline No & $4240(46.9)$ & $493(43.8)$ & & \\
\hline Multicomorbidity, $n(\%)$ & & & 0.072 & $<0.001$ \\
\hline None & $1598(17.7)$ & $80(9.1)$ & & \\
\hline Single & $2678(29.6)$ & $244(27.8)$ & & \\
\hline Multiple & $4766(52.7)$ & $554(63.1)$ & & \\
\hline Nutritional health, $n(\%)$ & & & 0.296 & $<0.001$ \\
\hline Good & $6688(74.0)$ & $370(42.1)$ & & \\
\hline Moderate risk & $1753(19.4)$ & $190(21.6)$ & & \\
\hline High risk & $601(6.6)$ & $318(36.2)$ & & \\
\hline Lower body muscle strength, $n(\%)$ & & & 0.174 & $<0.001$ \\
\hline Strong & $7588(84.1)$ & $530(60.5)$ & & \\
\hline Weak & 1437 (15.9) & $346(39.5)$ & & \\
\hline
\end{tabular}

Table 2 presents linear regression analysis results for GDS. GDS was negatively correlated with age $(p<0.001)$, BMI $(p<0.001)$, and lower-extremity muscle strength $(p<0.001)$ but positively with education $(p<0.001)$, multiple comorbidities $(p<0.001)$, and nutritional health risk $(p<0.001)$. 
Table 2. Linear regression for the determinants of Geriatric Depression Scale.

\begin{tabular}{lccccc}
\hline Variables & $\boldsymbol{\beta}$ & $\mathbf{9 5 \%} \mathbf{C I}$ & $\mathbf{r}^{\mathbf{2}}$ part & $\boldsymbol{p}$ Value & VIF \\
\hline Age & -0.010 & $-0.018 \sim-0.002$ & 0.005 & $<0.001$ & 1.475 \\
Gender & -0.003 & $-0.102 \sim 0.097$ & -0.004 & 0.510 & 1.385 \\
Body mass index & -0.032 & $-0.048 \sim-0.016$ & -0.041 & $<0.001$ & 1.024 \\
Education & 0.143 & $0.059 \sim 0.227$ & 0.001 & $<0.001$ & 1.409 \\
Smoking & 0.043 & $-0.101 \sim 0.309$ & -0.013 & 0.152 & 1.183 \\
Alcohol intake & 0.217 & $-0.126 \sim 0.089$ & 0.051 & 0.471 & 1.263 \\
Regular exercise & 0.004 & $-0.081 \sim 0.220$ & 0.002 & 0.271 & 1.054 \\
Multicomorbidity & 0.171 & $0.290 \sim 0.112$ & 0.012 & $<0.001$ & 1.125 \\
Nutritional health risk & 0.275 & $0.336 \sim 0.290$ & 0.354 & $<0.001$ & 1.103 \\
Lower extremity muscle strength & -0.340 & $-0.456 \sim-0.224$ & -0.117 & $<0.001$ & 1.157 \\
\hline CI: confidence interval; VIF: Variance
\end{tabular}

CI: confidence interval; VIF: variance inflation factor.

Table 3 presents logistic regression results of nutritional health risk and lower-extremity muscle strength for depression. Moderate (OR, 1.772; 95\% CI, 1.472-2.133) and high (OR, 7.703; 95\% CI, 6.450-9.199) nutritional health risks were significantly associated with greater odds for depression, compared with good health $(\mathrm{OR}, 1)$. The increased odds of moderate (OR, 1.679; 95\% CI, 1.385-2.035) and high (OR, 7.571; 95\% CI, 6.285-9.119) nutritional health risks for depression remained statistically significant even after adjustments for covariates of age, gender, BMI, education, smoking, alcohol intake, regular exercise, and multiple comorbidities. With respect to lower-extremity muscle strength, weak muscle strength was significantly associated with greater odds for depression (OR, 2.412; 95\% CI, 2.060-2.824), compared with strong muscle strength (OR, 1). The increased odds of weak muscle strength for the mental health condition remained statistically significant (OR, 2.094; 95\% CI, 1.770-2.476) even after adjustments for all covariates.

Table 3. Odds ratios (ORs) and 95\% confidence intervals (CIs) of depression by nutritional health and lower body strength.

\begin{tabular}{|c|c|c|c|c|}
\hline \multirow{2}{*}{ Predictors } & \multicolumn{2}{|c|}{ Model 1} & \multicolumn{2}{|c|}{ Model 2} \\
\hline & OR $(95 \%$ CI $)$ & $p$ Value & OR $(95 \%$ CI $)$ & $p$ Value \\
\hline \multicolumn{5}{|c|}{ Nutritional health risk } \\
\hline Good & 1 (reference) & & 1 (reference) & \\
\hline Moderate risk & $1.772(1.472 \sim 2.133)$ & $<0.001$ & $1.679(1.385 \sim 2.035)$ & $<0.001$ \\
\hline High risk & 7.703 (6.450 9.199) & $<0.001$ & $7.571(6.285 \sim 9.119)$ & $<0.001$ \\
\hline \multicolumn{5}{|c|}{ Lower extremity muscle strength } \\
\hline Strong & 1 (reference) & & 1 (reference) & \\
\hline Weak & $2.412(2.060 \sim 2.824)$ & $<0.001$ & $2.094(1.770 \sim 2.476)$ & $<0.001$ \\
\hline
\end{tabular}

Model 1 unadjusted. Model 2 adjusted for age, gender, body mass index, education, smoking, alcohol intake, regular exercise, and multicomorbidity.

Table 4 presents the relationship between nutritional health risk (x) and GDS (y) moderated by lower-extremity muscle strength $(\mathrm{w})$. There was a significant moderating effect of lower-extremity muscle strength for the relationship between nutritional health risk and depression $(\beta=-0.127 ; 95 \% \mathrm{CI},-0.157$ to -0.097$)$. The moderating effect of lower-extremity muscle strength remained significant $(\beta=-0.120 ; 95 \% \mathrm{CI},-0.173$ to -0.067 ) after adjustments for the covariates. Additionally, we probed the interaction to better interpret the moderating effect of lower-extremity muscle strength on the relationship between nutritional health risk and GDS; the weaker was the muscle strength, the steeper was the slope of GDS concerning the effect on nutritional health risk (Figure 3). 
Table 4. A moderation analysis of lower body strength for the relationship between nutritional health and Geriatric Depression Scale.

\begin{tabular}{|c|c|c|c|c|c|c|}
\hline \multirow{2}{*}{ Predictors } & \multirow{2}{*}{ Coefficients } & \multirow{2}{*}{ SE } & \multirow{2}{*}{$\mathbf{t}$} & \multirow{2}{*}{$p$} & \multicolumn{2}{|c|}{$95 \% \mathrm{CI}$} \\
\hline & & & & & Lower & Upper \\
\hline \multicolumn{7}{|c|}{ Model $1\left(\mathrm{R}^{2}=0.133, \mathrm{~F}=506.561, p<0.001\right)$} \\
\hline Nutritional health & 0.472 & 0.026 & 18.064 & $<0.001$ & 3.736 & 4.256 \\
\hline Lower body strength & 0.110 & 0.071 & 1.562 & 0.118 & -0.028 & 0.249 \\
\hline Interaction & -0.127 & 0.015 & -8.342 & $<0.001$ & -0.157 & -0.097 \\
\hline \multicolumn{7}{|c|}{$\mathrm{R}^{2}$ change due to the moderator $=0.006(\mathrm{~F}=69.59, p<0.001)$} \\
\hline \multicolumn{7}{|c|}{ Model $2\left(\mathrm{R}^{2}=0.162, \mathrm{~F}=71.006, p<0.001\right)$} \\
\hline Nutritional health & 0.494 & 0.046 & 10.680 & $<0.001$ & 0.403 & 0.584 \\
\hline Lower body strength & -0.356 & 0.133 & -2.673 & 0.008 & -0.617 & -0.095 \\
\hline Interaction & -0.120 & 0.027 & -4.451 & $<0.001$ & -0.173 & -0.067 \\
\hline \multicolumn{7}{|c|}{$\mathrm{R}^{2}$ change due to the moderator $=0.005(\mathrm{~F}=19.809, p<0.001)$} \\
\hline
\end{tabular}

Model 1 unadjusted. Model 2 adjusted for age, gender, body mass index, education, smoking, alcohol intake, regular exercise, and multicomorbidity. SE: standard error; CI: confidence interval.

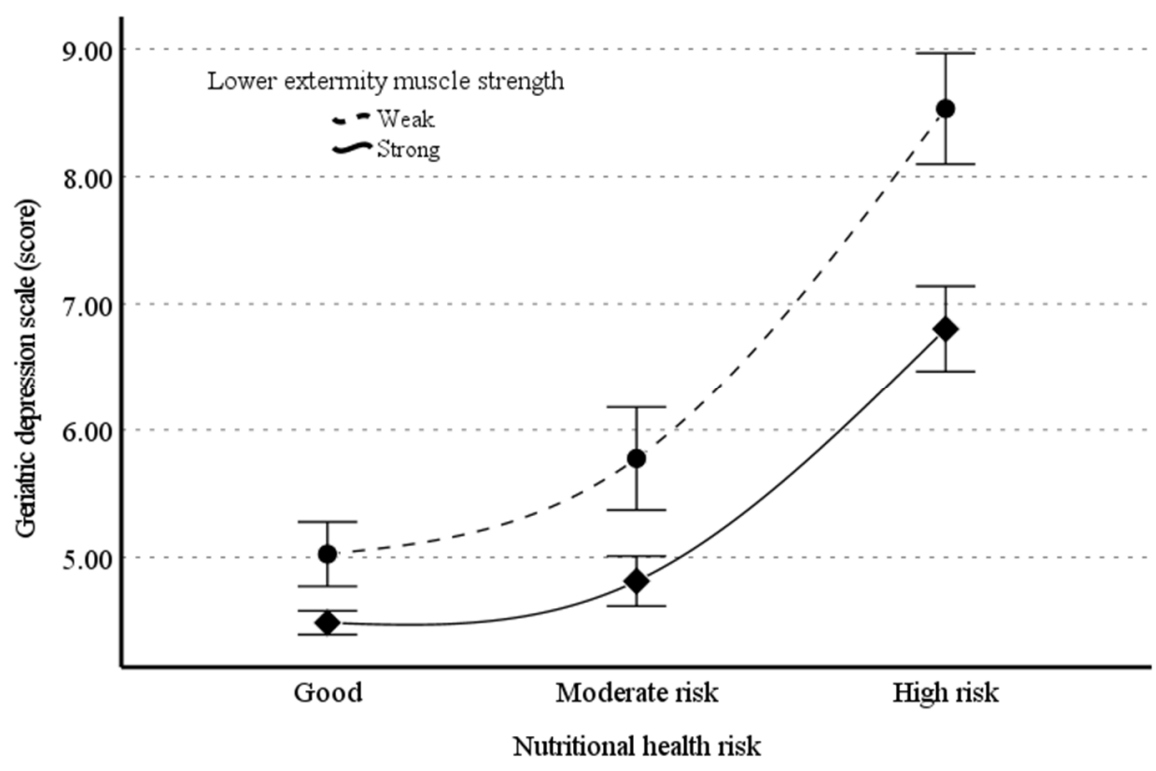

Figure 3. Illustration of the moderating effect of lower extremity muscle strength on the relationship between nutritional health risk and Geriatric Depression Scale.

\section{Discussion}

In this population-based cross-sectional study, we examined the impacts of lowerextremity muscle strength and nutritional health risk on depression in 9920 Korean older adults aged $\geq 65$ years and found that nutritional health risk and weak lower-extremity muscle strength were associated with greater odds for late-in-life depression. The novel finding of the current study is that the weaker was the muscle strength, the greater was the impact of nutritional health risk on depression.

The current findings are in accordance with those of previous studies reporting an association between nutritional status and depression in older adults. For example, malnutrition was found to be an independent risk factor for depression in older outpatients in Turkey [32] and community-dwelling older individuals in Bangladesh [33] and China [34]. Poor dietary quality was significantly associated with postpartum depression in a sample of 939 Chinese lactating women [35]. An association between nutritional health risk and depression was also reported by previous studies involving Korean older adults with multiple chronic diseases [36] and community-dwelling Korean older adults [19]. Additionally, food insecurity and poor nutritional status were associated with greater odds for depression in Korean older adults with low incomes [37] and community-dwelling Korean older adults [18], respectively. By contrast, high consumption of fruits, vegetables, low-fat 
dairy, and antioxidants is inversely associated with depression risk. Additionally, the consumption of specific nutrients, including calcium, chromium, folate, polyunsaturated fatty acids, vitamins, zinc, and magnesium also has antidepressant effects [38,39]. Consequently, the findings of the current study suggest that a healthy diet such as a Mediterranean diet should be recommended as a therapeutic approach against late-life depression.

The findings of the current study are also in line with those of previous studies reporting an association between weak muscle strength and depression in older adults. For example, several previous studies using data obtained from the Korea National Health and Nutrition Examination Survey showed that handgrip strength was inversely associated with depression risk and suicidal ideation in Korean middle-aged and older adults [40,41]. In a cross-sectional study involving 562 community-dwelling Korean men and women aged $\geq 65$ years, we showed that lower muscle mass and lower muscle function were individually and synergistically associated with greater odds of depressive symptoms [9]. In 1100 Singaporean women aged 45-69 years, Ganasarajah et al. [42] showed that weak muscle strength was significantly associated with greater odds of depression and/or anxiety symptoms. A recent meta-analysis of 33 results obtained from 16 studies effectively summarizes the inverse associations between muscle strength and late-in-life depression risk [43].

In particular, the findings of this study extend those of previous studies by showing that muscle strength is an important moderator in determining the relationship between nutritional health risk and late-in-life depression. The moderating effect of lower-extremity muscle strength on the relationship implies the clinical importance of both good nutrition and muscle fitness as a therapeutic strategy against late-in-life depression. In support of the current findings, Pinheiro et al. [44] conducted a 12-week randomized control trial of sarcopenic elderly women and showed that a combination of nutritional intervention and group-based functional exercise is more effective at relieving depressive symptoms and social isolation, compared with a single intervention, such as nutritional intervention or socialization activities. In a cross-sectional study involving 130 community-dwelling Japanese older adults, Kaburagi et al. [45] found that adequate nutritional status was positively associated with handgrip strength and maximum walking speed but negatively associated with GDS score, implying a pathologic connection between nutrition, physical fitness, and mental health. In this aspect, muscle strength might reflect nutritional health status, or vice versa, which contributes to mental health. However, the exact direction of the relationship cannot be determined due to the cross-sectional nature of the study.

Some explanations are possible regarding the modulating effect of lower-extremity muscle strength on the relationship between nutritional health risks and late-in-life depression. First, chronic exposure to nutritional health risks might lead to or exacerbate geriatric conditions that contribute to depression, such as functional limitations [46], physical disabilities [47], and sarcopenia [48]. Consequently, the moderating effect of lower-extremity muscle strength on the relationship between nutritional health risk and depression might reflect an intermediate phenotype linking nutritional health risk to mental illness. However, the exact mechanism(s) by which muscle strength attenuates the negative effect of nutritional health risk on mental health must be determined.

Second, maintaining muscle mass and strength itself may minimize or counteract the risk of late-in-life depression [49]. For example, strong muscle strength is associated with physical independence, fewer difficulties performing daily activities, lower risk for experiencing physical disabilities, and better quality of life [50,51]. Furthermore, muscle contraction has an anti-depressant effect by suppressing pro-inflammatory responses (i.e., decreased levels of circulating tumor necrosis factor- $\alpha$ and interleukin 6) while enhancing anti-inflammatory responses (i.e., increased levels of circulating interleukin-10 and brainderived neurotrophic factor) [52,53].

Third, other health conditions, such as chronic diseases, increased oxidative stress, immobility, and dysregulated hormonal cycles, which are attributed to nutritional health risk and/or weak muscle strength, might be involved in the moderating effect of lower- 
extremity muscle strength on the relationship between nutritional health risk and depression $[49,54]$.

Lastly, poor socio-economic status (i.e., poverty, living alone, low education, and illiteracy) and poor health behaviors (i.e., smoking and heavy alcohol consumption) may be entangled in the moderating effect of lower extremity muscle strength on the relationship between nutritional health status and late-life depression [55]. The involvement of those risk factors in the interconnection between muscle strength and nutritional health risk on depressive symptoms remains to be investigated in a future study.

This study is not without limitations. First, the cross-sectional nature of this study does not allow us to offer any cause-and-effect interpretation regarding the moderating effect of lower-extremity muscle strength on the relationship between nutritional health risk and depression. Second, the relationships of nutritional health risk and lower-extremity muscle strength with depression can be bidirectional. In other words, either nutritional health risk or lower-extremity muscle strength or both can increase the risk for depression, or vice versa, and this remains to be addressed in a well-designed intervention study. Third, the relationships of nutritional health risk and lower-extremity muscle strength with late-in-life depression may imply adverse effects of other health conditions that are not included in the current study. Consequently, caution is necessary when interpreting the moderating effect of muscle strength on the relationship between nutritional health risk and depression.

Despite these limitations, this study also has strengths. First, it is a population-based study with large sample size. Second, to the best of our knowledge, we are the first to report the potential of lower-extremity muscle strength as an important moderator in determining the relationship between nutritional health risk and depression in older adults.

\section{Conclusions}

In this population-based study, we examined the relationships of nutritional health risk and lower-extremity muscle strength with depression in Korean older adults and found that late-in-life depression was positively associated with nutritional health risk and inversely with lower-extremity muscle strength. Particularly, we found that high lower-extremity muscle strength attenuates the negative impact of nutritional health risk on depression, implying an urgency of an intervention targeting both nutritional health risks and weak muscle strength as a therapeutic strategy against depression in Korean older adults.

Author Contributions: Conceptualization, H.K. and J.K.; methodology, H.K., J.K., H.H. and S.K.; formal analysis, H.K., J.K., H.H., S.K., J.-H.K. and S.-K.W.; investigation, H.K., J.K., H.H. and S.K.; data curation, H.K., J.K., H.H. and S.K.; writing-original draft preparation, H.K., J.K. and S.K.; writing-review and editing, H.K., J.K., H.H., S.K., J.-H.K. and S.-K.W.; visualization, H.K., J.K., S.K., J.-H.K. and S.-K.W.; funding acquisition, H.H. All authors have read and agreed to the published version of the manuscript.

Funding: This study was supported by a National Research Foundation grant funded by the Korean government (NRF-2020R1A2C1009365).

Institutional Review Board Statement: The Institutional Review Board of the Korea Institute for Health and Social Affairs reviewed and approved the 2020 KLoSA (approval number: 2020-36/ approved on 24 March 2020) in accordance with the Declaration of Helsinki.

Informed Consent Statement: Informed consent forms were obtained from all the participants.

Data Availability Statement: Data are accessible via the National public database (https:/ / survey. keis.or.kr/eng/myinfo/login.jsp/ accessed 10 June 2021).

Acknowledgments: We gratefully thank the Korea Employment Information Service (KEIS) for allowing the use of their data for this study.

Conflicts of Interest: All the authors declare that they have no conflict of interest. 


\section{References}

1. Song, J.; Koh, T.H.; Park, O.; Kwon, D.; Kang, S.; Kwak, K.; Park, J.T. Association between depression and cardiovascular disease risk in general population of Korea: Results from the Korea national health and nutrition examination survey, 2016. Ann. Occup. Environ. Med. 2019, 31, e10. [CrossRef] [PubMed]

2. Kim, H.; Jeong, W.; Kwon, J.; Kim, Y.; Park, E.-C.; Jang, S.-I. Association between depression and the risk of Alzheimer's disease using the Korean national health insurance service-elderly cohort. Sci. Rep. 2021, 11, 22591. [CrossRef] [PubMed]

3. Kim, B.J.; Kihl, T. Suicidal ideation associated with depression and social support: A survey-based analysis of older adults in South Korea. BMC Psychiatry 2021, 21, 409. [CrossRef] [PubMed]

4. Kim, H.; Kim, S.H.; Cho, Y.J. Combined effects of depression and chronic disease on the risk of mortality: The Korean longitudinal study of aging (2006-2016). J. Korean Med. Sci. 2021, 36, e99. [CrossRef]

5. Shin, D.; Kim, N.W.; Kim, M.J.; Rhee, S.J.; Park, C.H.K.; Kim, H.; Yang, B.R.; Kim, M.S.; Choi, G.J.; Koh, M.; et al. Cost analysis of depression using the national insurance system in South Korea: A comparison of depression and treatment-resistant depression. BMC Health Serv. Res. 2020, 20, 286. [CrossRef]

6. He, Q.; Yang, L.; Shi, S.; Gao, J.; Tao, M.; Zhang, K.; Gao, C.; Yang, L.; Li, K.; Shi, J.; et al. Smoking and major depressive disorder in Chinese women. PLoS ONE 2014, 9, e106287. [CrossRef]

7. Choi, N.G.; Dinitto, D.M. Heavy/binge drinking and depressive symptoms in older adults: Gender differences. Int. J. Geriatr. Psychiatry 2011, 26, 860-868. [CrossRef]

8. Meng, X.; D'Arcy, C. The projected effect of increasing physical activity on reducing the prevalence of common mental disorders among Canadian men and women: A national population-based community study. Prev. Med. 2013, 56, 59-63. [CrossRef]

9. Jin, Y.; Kang, S.; Kang, H. Individual and synergistic relationships of low muscle mass and low muscle function with depressive symptoms in Korean older adults. Int. J. Environ. Res. Public Health 2021, 18, 10129. [CrossRef]

10. Marques, A.; Henriques-Neto, D.; Peralta, M.; Marconcin, P.; Gouveia, É.R.; Ferrari, G.; Martins, J.; Ihle, A. Exploring grip strength as a predictor of depression in middle-aged and older adults. Sci. Rep. 2021, 11, 15946. [CrossRef]

11. Aarden, J.J.; van der Schaaf, M.; van der Esch, M.; Reichardt, L.A.; van Seben, R.; Bosch, J.A.; Twisk, J.W.R.; Buurman, B.M.; Engelbert, R.H.H.; Hospital-ADL Study Group. Muscle strength is longitudinally associated with mobility among older adults after acute hospitalization: The Hospital-ADL study. PLoS ONE 2019, 14, e0219041. [CrossRef] [PubMed]

12. Ho, H.H.; Fang, I.Y.; Yu, Y.C.; Huang, Y.P.; Kuo, I.L.; Wang, L.T.; Tsai, M.C.; Chang, S.H.; Hsueh, M.C. Is functional fitness performance a useful predictor of risk of falls among community-dwelling older adults? Arch. Public Health 2021, 79, 108. [CrossRef] [PubMed]

13. Bae, E.J.; Park, N.J.; Sohn, H.S.; Kim, Y.H. Handgrip strength and all-cause mortality in middle-aged and older Koreans. Int. J. Environ. Res. Public Health 2019, 16, 740. [CrossRef]

14. Noh, H.M.; Park, Y.S. Handgrip strength, dynapenia, and mental health in older Koreans. Sci. Rep. 2020, 10, 4004. [CrossRef] [PubMed]

15. Davison, K.M.; Lung, Y.; Lin, S.L.; Tong, H.; Kobayashi, K.M.; Fuller-Thomson, E. Depression in middle and older adulthood: The role of immigration, nutrition, and other determinants of health in the Canadian longitudinal study on aging. BMC Psychiatry 2019, 19, 329. [CrossRef]

16. Taylor, K.L.; Simpson, S., Jr.; Jelinek, G.A.; Neate, S.L.; De Livera, A.M.; Brown, C.R.; O'Kearney, E.; Marck, C.H.; Weiland, T.J. Longitudinal associations of modifiable lifestyle factors with positive depression-screen over 2.5-years in an international cohort of people living with multiple sclerosis. Front. Psychiatry 2018, 9, 526. [CrossRef]

17. Khosravi, M.; Sotoudeh, G.; Majdzadeh, R.; Nejati, S.; Darabi, S.; Raisi, F.; Esmaillzadeh, A.; Sorayani, M. Healthy and unhealthy dietary patterns are related to depression: A case-control study. Psychiatry Investig. 2015, 12, 434-442. [CrossRef]

18. Lee, E.J.; Kim, J.M. Associations between depression and eating behavior factors in Korean adults: The Korea national health and nutrition examination survey 2018. J. Nutr. Health 2021, 54, 152-164. [CrossRef]

19. Song, E.G.; Yoon, Y.S.; Yang, Y.J.; Lee, E.S.; Lee, J.H.; Lee, J.Y.; Park, W.J.; Park, S.Y. Factors associated with eating alone in Korean adults: Findings from the sixth Korea national health and nutrition examination, 2014. Korean J. Fam. Pract. 2017, 7, 698-706. [CrossRef]

20. Park, S.; Cho, J.; Kim, D.; Jin, Y.; Lee, I.; Hong, H.; Kang, H. Handgrip strength, depression, and all-cause mortality in Korean older adults. BMC Geriatr. 2019, 19, 127. [CrossRef]

21. Park, J.H.; Kim, K.W. A review of the epidemiology of depression in Korea. J. Korean Med. Assoc. 2011, 554, 362-369. [CrossRef]

22. Cavazzana, A.; Röhrborn, A.; Garthus-Niegel, S.; Larsson, M.; Hummel, T.; Croy, I. Sensory-specific impairment among older people. An investigation using both sensory thresholds and subjective measures across the five senses. PLoS ONE 2018, 13, e0202969. [CrossRef] [PubMed]

23. Leslie, W.; Hankey, C. Aging, nutritional status and health. Healthcare 2015, 3, 648-658. [CrossRef] [PubMed]

24. Wilkinson, D.J.; Piasecki, M.; Atherton, P.J. The age-related loss of skeletal muscle mass and function: Measurement and physiology of muscle fibre atrophy and muscle fibre loss in humans. Ageing Res. Rev. 2018, 47, 123-132. [CrossRef] [PubMed]

25. Štefan, L.; Petrinović, L.; Sporiš, G.; Vrgoč, G. Frequency of dietary intake and physical activity in older adults: A cross-sectional study. Nutrients 2018, 10, 1960. [CrossRef] [PubMed] 
26. Castro-Mejía, J.L.; Khakimov, B.; Krych, Ł.; Bülow, J.; Bechshøft, R.L.; Højfeldt, G.; Mertz, K.H.; Garne, E.S.; Schacht, S.R.; Ahmad, H.F.; et al. Physical fitness in community-dwelling older adults is linked to dietary intake, gut microbiota, and metabolomic signatures. Aging Cell 2020, 19, e13105. [CrossRef] [PubMed]

27. Bae, J.N.; Cho, M.J. Development of the Korean version of the geriatric depression scale and its short form among elderly psychiatric patients. J. Psychosom. Res. 2004, 57, 297-305. [CrossRef]

28. Lee, S.C.; Kim, W.H.; Chang, S.M.; Kim, B.S.; Lee, D.W.; Bae, J.N.; Cho, M.J. The use of the Korean version of short form geriatric depression scale (SGDS-K) in the community dwelling elderly in Korea. J. Korean Geriatr. Psychiatry 2013, 17, $37-43$.

29. Nutrition Screening Initiative. Report of Nutrition Screening 1: Toward a Common View: Executive Summary; A Consensus Conference, Nutrition Screening Initiative: Washington, DC, USA, 1991.

30. Posner, B.M.; Jette, A.M.; Smith, K.W.; Miller, D.R. Nutrition and health risks in the elderly: The nutritional screening initiative. Am. J. Public Health 1993, 83, 972-978. [CrossRef]

31. Buatois, S.; Miljkovic, D.; Manckoundia, P.; Gueguen, R.; Miget, P.; Vancon, G.; Perrin, P.; Benetos, A. Five times sit to stand test is a predictor of recurrent falls in healthy community-living subjects aged 65 and older. J. Am. Geriatr. Soc. 2008, 56, 1575-1577. [CrossRef]

32. Delibaş, D.H.; Eşkut, N.; İlhan, B.; Erdoğan, E.; Top Kartı, D.; Yılmaz Küsbeci, Ö..; Bahat, G. Clarifying the relationship between sarcopenia and depression in geriatric outpatients. Aging Male 2021, 24, 29-36. [CrossRef] [PubMed]

33. Alam, M.R.; Karmokar, S.; Reza, S.; Kabir, M.R.; Ghosh, S.; Mamun, M.A.A. Geriatric malnutrition and depression: Evidence from elderly home care population in Bangladesh. Prev. Med. Rep. 2021, 23, 101478. [CrossRef] [PubMed]

34. Wei, J.; Fan, L.; Zhang, Y.; Li, S.; Partridge, J.; Claytor, L.; Sulo, S. Association between malnutrition and depression among community-dwelling older Chinese adults. Asia Pac. J. Public Health 2018, 30, 107-117. [CrossRef] [PubMed]

35. Yang, C.; Zhao, A.; Lan, H.; Ren, Z.; Zhang, J.; Szeto, I.M.; Wang, P.; Zhang, Y. Association between dietary quality and postpartum depression in lactating women: A cross-sectional survey in urban China. Front. Nutr. 2021, 8, 705353. [CrossRef]

36. Shin, S.; Hwang, E. Factors influencing depressive symptoms among Korean older adults with chronic illnesses: Using the 2014 national survey on older adults. Korean J. Adult Nurs. 2018, 30, 577-585. [CrossRef]

37. Kim, G.E.; Jo, M.W.; Shin, Y.W. Increased prevalence of depression in South Korea from 2002 to 2013. Sci. Rep. 2020, 10, 16979. [CrossRef]

38. Lang, U.E.; Beglinger, C.; Schweinfurth, N.; Walter, M.; Borgwardt, S. Nutritional aspects of depression. Cell Physiol. Biochem. 2015, 37, 1029-1043. [CrossRef]

39. Li, Y.; Lv, M.R.; Wei, Y.J.; Sun, L.; Zhang, J.X.; Zhang, H.G.; Li, B. Dietary patterns and depression risk: A meta-analysis. Psychiatry Res. 2017, 253, 373-382. [CrossRef]

40. Lee, M.R.; Jung, S.M.; Bang, H.; Kim, H.S.; Kim, Y.B. The association between muscular strength and depression in Korean adults: A cross-sectional analysis of the sixth Korea national health and nutrition examination survey (KNHANES VI) 2014. BMC Public Health 2018, 18, 1123. [CrossRef]

41. Hurh, K.; Park, Y.; Kim, G.R.; Jang, S.I.; Park, E.C. Associations of handgrip strength and handgrip strength asymmetry with depression in the elderly in Korea: A cross-sectional study. J. Prev. Med. Public Health 2021, 54, 63-72. [CrossRef]

42. Ganasarajah, S.; Sundström Poromaa, I.; Thu, W.P.; Kramer, M.S.; Logan, S.; Cauley, J.A.; Yong, E.L. Objective measures of physical performance associated with depression and/or anxiety in midlife Singaporean women. Menopause 2019, 26, 1045-1051. [CrossRef] [PubMed]

43. Zasadzka, E.; Pieczyńska, A.; Trzmiel, T.; Kleka, P.; Pawlaczyk, M. Correlation between handgrip strength and depression in older adults-A systematic review and a meta-analysis. Int. J. Environ. Res. Public Health 2021, 18, 4823. [CrossRef] [PubMed]

44. Pinheiro, H.A.; Cerceau, V.R.; Pereira, L.C.; Funghetto, S.S.; de Menezes, R.L. Nutritional intervention and functional exercises improve depression, loneliness and quality of life in elderly women with sarcopenia: A randomized clinical trial. Fisioter. Mov. 2020, 33, e003332. [CrossRef]

45. Kaburagi, T.; Hirasawa, R.; Yoshino, H.; Odaka, Y.; Satomi, M.; Nakano, M.; Fujimoto, E.; Kabasawa, K.; Sato, K. Nutritional status is strongly correlated with grip strength and depression in community-living elderly Japanese. Public Health Nutr. 2011, 14, 1893-1899. [CrossRef]

46. Song, Y.; Liu, M.; Jia, W.P.; Han, K.; Wang, S.S.; He, Y. The association between nutritional status and functional limitations among centenarians: A cross-sectional study. BMC Geriatr. 2021, 21, 376. [CrossRef]

47. Pigłowska, M.; Guligowska, A.; Kostka, T. Nutritional status plays more important role in determining functional state in older people living in the community than in nursing home residents. Nutrients 2020, 12, 2042. [CrossRef]

48. Sieber, C.C. Malnutrition and sarcopenia. Aging Clin. Exp. Res. 2019, 31, 793-798. [CrossRef]

49. Marques, A.; Gomez-Baya, D.; Peralta, M.; Frasquilho, D.; Santos, T.; Martins, J.; Ferrari, G.; Gaspar de Matos, M. The effect of muscular strength on depression symptoms in adults: A systematic review and meta-analysis. Int. J. Environ. Res. Public Health 2020, 17, 5674. [CrossRef]

50. Kim, S.; Choe, K.; Lee, K. Depression, loneliness, social support, activities of daily living, and life satisfaction in older adults at high-risk of dementia. Int. J. Environ. Res. Public Health 2020, 17, 9448. [CrossRef]

51. Dos Santos, L.; Cyrino, E.S.; Antunes, M.; Santos, D.A.; Sardinha, L.B. Sarcopenia and physical independence in older adults: The independent and synergic role of muscle mass and muscle function. J. Cachexia Sarcopenia Muscle 2017, 8, 245-250. [CrossRef] 
52. Santoft, F.; Hedman-Lagerlöf, E.; Salomonsson, S.; Lindsäter, E.; Ljótsson, B.; Kecklund, G.; Lekander, M.; Andreasson, A. Inflammatory cytokines in patients with common mental disorders treated with cognitive behavior therapy. Brain Behav. Immun. Health 2020, 3, 100045. [CrossRef] [PubMed]

53. Kim, S.; Choi, J.Y.; Moon, S.; Park, D.H.; Kwak, H.B.; Kang, J.H. Roles of myokines in exercise-induced improvement of neuropsychiatric function. Pflugers Arch. Eur. J. Physiol. 2019, 471, 491-505. [CrossRef] [PubMed]

54. Sgro, P.; Sansone, M.; Sansone, A.; Sabatini, S.; Borrione, P.; Romanelli, F.; Di Luigi, L. Physical exercise, nutrition, and hormones: Three pillars to fight sarcopenia. Aging Male 2019, 22, 75-88. [CrossRef] [PubMed]

55. Park, J.H.; Kim, K.W.; Kim, M.H.; Kim, M.D.; Kim, B.J.; Kim, S.K.; Kim, J.L.; Moon, S.W.; Bae, J.N.; Woo, J.I.; et al. A nationwide survey on the prevalence and risk factors of late life depression in South Korea. J. Affect. Disord. 2012, 138, 34-40. [CrossRef] 